\title{
Rastgele Orman Yöntemi Kullanılarak Kıyı Çizgisi Çıkarımı İstanbul Örneği
}

\author{
Fırat Erdem ${ }^{1 *}$, Mustafa Andaç Derinpınar ${ }^{1}$, Rouhollah Nasirzadehdizaji ${ }^{1}$, Selen $\mathrm{Oy}^{2}$, Dursun Zafer \\ Şeker ${ }^{3}$, Bülent Bayram ${ }^{1}$ \\ ${ }^{1}$ Yıldız Teknik Üniversitesi, İnşaat Fakültesi, 34220 Davutpaşa İstanbul ((firat.erdem, mustafa.andac.derinpinar, \\ rouhollah.nasirzadehdizaji)@std.yildiz.edu.tr, bayram@yildiz.edu.tr) \\ ORCID ID 0000- 0002-6163-1979, ORCID ID 0000- 0003-1223-5125, ORCID ID 0002-1830-6492, \\ ORCID ID 0000- 0002-4248-116X \\ ${ }^{2}$ Akdeniz Üniversitesi, Uzaktan Algılama Araştırma ve Uygulama Merkezi, 07058 Antalya (selenoy171@gmail.com) \\ ORCID ID 0000- 0002-0741-1684 \\ ${ }^{3}$ İstanbul Teknik Üniversitesi, Geomatik Mühendisliği Bölümü, 34469, Maslak, İstanbul (seker@itu.edu.tr) \\ ORCID ID 0000- 0001-7498-1540
}

\section{$\ddot{O} z$}

Çevrenin korunması ve sürdürülebilir kıyı geliştirme hedeflerine ulaşmak için kıyı alanlarının izlenmesi gerekmektedir. Doğal çevre yönetimi, afet yönetimi, kıyı erozyonu incelemeleri, katı madde taşınımı ve kıyı morfodinamiklerinin modellemesi gibi farklı alanlarda kıyı çizgisi yaygın olarak kullanıldığından, kıyı çizgilerinin özellikle uydu görüntülerinden çıkarılması için çeşitli teknikler geliştirilmiştir. Rastgele Orman algoritması geliştirilen bu tekniklerden bir tanesidir. Rastgele Orman Algoritması, karar ağaçlarına dayanan bir makine öğrenme metodudur. Karar ağaçları, eğitim verilerinin sınıflarını analiz eder ve test verilerinin hangi sınıfa ait olduğunu eğitim verilerinden çıkarttığı kurallara göre belirler. Bu çalışmada, Terkos Gölü ve gölün hemen yakınında yer aldığı bölgedeki Karadeniz sahilindeki kıyı çizgileri, 22 Temmuz 2016 tarihinde alınan Landsat-8 uydu görüntüsüne Rastgele Orman sınıflandırma yöntemi kullanılarak çıkarılmıştır. Uygulamada öncelikle uydu görüntüsüne ön işleme uygulanmıştır. Rastgele Orman algoritması ile sınıflandırma işlemi için MATLAB platformu kullanılmıştır. Rastgele Orman algoritması çalışma bölgelerine ait görüntülerin farklı bant setlerine uygulanarak, sınıflandırma işlemi gerçekleştirilmiştir. Sınıflandırma sonucunda kara ve su sınıfları olmak üzere ikili görüntüler elde edilmiştir. Uygulanan bant setleri NIR, R-G-B ve R-G-B-NIR'dir. Terkos Gölü'ne ait elde edilen kıyı çizgilerinin doğruluklarını analiz etmek için elle sayısallaştırılan kıyı çizgileri referans alınarak alansal ve kıyı çizgisi bazında karşılaştırılmıştır. Sonuçlara bakıldığında, kıyı çizgisi çıkarımında yakın kızıl ötesi bandını içeren görüntülerin en az hatalı sonucu verdiği görülmüştür.

\section{Coastline Extraction By Using Random Forest Method; A Case Study Of Istanbul}

\begin{abstract}
Coastal monitoring plays a vital role in environmental planning and hazard management related issues. Since shorelines are basic data for natural environment management, disaster management, coastal erosion studies, modelling of sediment transport and coastal morphodynamics, various techniques have been developed to extract coastlines. Random Forest is one of these techniques which is used in this study for shoreline extraction purpose. This algorithm is a machine learning method based on decision trees. Decision trees analyse classes
\end{abstract}

\footnotetext{
* Sorumlu Yazar
} 
of training data creates rules for classification. In this study, proposed Random Forest algorithm has been implemented to extract the shoreline of the Terkos Lake and Black Sea where near the lake from Landsat-8 image taken on 22 July 2016. The Landsat- 8 image firstly pre-processed. The MATLAB environment was used for classification. To obtain land and water-body classes, the Random Forest method has been applied to NIR, R-G-B and R-G-B-NIR band sets. Manually digitized shorelines have been used for accuracy assessment. Areal and shoreline based evaluations have been done for Lake Terkos and Black Sea shoreline. According to accuracy assessment results, satisfactory results have been achieved by the proposed method. It has been seen once that most accurate results were obtained with data sets containing NIR band.

Keywords: Random Forest Classifier, Shoreline extraction, Landsat-8, Remote Sensing

\section{GíRIŞ}

Atmosfer, hidrosfer ve yerkürenin birbirleri ile etkileşim içerisinde oldukları yegâne alanlar olan kıyı bölgelerindeki koşulların büyük bir bölümünün, yıllık, mevsimsel ve hatta günlük olarak insan etkisinde veya firtına ve iklim değişikliği gibi doğal kaynaklı değişime uğraması, bu değişimlerin belirli bölgelerde ve zamanlarda, belirli periyodlarla izlenerek saptanmasını gerektirir. Doğal gelişim ve çevresel koruma açısından oldukça önemli olan bu işlemlerin klasik yöntemlerle yapılmasının oldukça zaman alıcı olması nedeniyle, uzaktan algilama teknolojileri yaygın olarak kullanılabilmektedir (Bayram, vd., 2017). Kıyı değişimlerinin izlenmesi on y1llar boyu araştırmaların konusu olmuştur (Dornbusch, vd., 2006; Marques, 2006; Pierre ve Lahousse, 2006; Benumof ve Griggs, 1999). Kara ile denizin sürekli etkileşim içinde olduğu kıyı alanları en çok tehdit altında olan eko-sistemlerden biridir. Kıy1 alanları artan nüfus, şehirleşme ile artan bir oranda insan tehdidi altındadır ve eko-sistemi tehdit etmektedir (Bendell ve Wan, 2011). Uluslararası Coğrafi Veri Komitesi' ne göre kıyı alanları yeryüzündeki en önemli 27 doğal zenginliklerden biridir ( $\mathrm{Li}$, vd., 2001). Bu nedenle kıyı alanlarının periyodik olarak izlenmesi ve değişimlerin analiz edilmesi gerekmektedir.

Kıyı çizgisi çıkartmaya ve kıyı alanlarının izlenmesine yönelik önerilen yöntemler temel olarak yersel ölçüler, fotogrametrik yöntemler, uzaktan algilama verileri ve teknikleri kullanılarak geliştirilmiştir (Gens, 2010). Optik uzaktan algilama verileri kullanılarak kıyılara ilişkin güncel, doğru, zamansal ve güvenilir bilgiler elde edilebilir (Kutser, vd., 2012). Uzaktan algilama tekniği ile kıyı alanlarının izlenmesi, yersel ölçümler ile yapılması olanaksız anlık ve zamansal verilerin elde edilmesi olanaklıdır (Trochta, vd., 2015). 30m mekânsal çözünürlüğe sahip Landsat görüntüleri, kıyı alanlarının izlenmesi için oldukça uygundur (Robert, vd., 2004). Piksel ve nesne-tabanlı görüntü işleme yöntemleri uydu verilerinden kıy çizgisi çıkartmak amacıyla kullanılmaktadır (Machado, vd., 2014; Song, vd., 2014). Kontrolsüz siniflandirma teknikleri (ISODATA-Iterative Self Organized Data Analysis) (Guariglia, vd., 2006), su indeksleri (NDWI) (Zheng, vd., 2011), eşik değer ve morfolojik filtreleme teknikleri (Pardo Pascual, vd., 2012), Wavelet dönüşümü (Yu, vd., 2013), aktif kontur modeli (Schmitt, vd., 2015), genetik algoritma temelli yöntemler (Yousef ve Iftekharuddin, 2014), parçacık sürü optimizayonu (PSO) (Bayram, vd., 2016a), Mean-shift bölütleme (Bayram, vd., 2016b), nesne-tabanlı bulanık sinıflandırma yöntemleri (Bayram, vd., 2013; Bayram, vd., 2008), normalleştirilmiş kesme yaklaşımı (Ding ve Li, 2014) kıyı çizgisi çıkartmaya yönelik önerilen yöntemlere örnek olarak verilebilir. Sunulan çalışmada Rastgele Orman (RO) siniflandırma algoritmas1 (Breiman, 2001) kullanılarak 2016 y1lına ait Landsat-8 görüntüsünden çalışma alanı olarak seçilen Terkos Gölü kıyı çizgisi ve gölün Karadeniz'e komşu olduğu yerde kıyı çizgisi çıkartılmıştır.

\section{CALIŞMA ALANI}

Çalışma alanı İstanbul-Terkos Gölünün kuzeyinde kalan yaklaşık $30 \mathrm{~km}$ uzunluğundaki Karadeniz kıyı şerididir. Terkos Gölü, tüm Türkiye'deki şebeke suyuna ismini vermiş ilk içme suyu kaynağıdır. Göl İstanbul su sistemi içinde Avrupa yakasının 
yaklaşık yüzde 95'ini, tüm İstanbul'un su ihtiyacının ise yaklaşık yüzde 40'ını karşılamakta olan en önemli su kaynaklarından birisidir. Terkos Gölü, Karadeniz kıyı şeridinde dalga ve akıntı etkilerinin yanı sıra bilimsel yöntemlere dayanmayan kum alımları ve hatalı kıyı tahkimatları nedeniyle Karadeniz'in tuzlu suyunun nüfuz etme riskiyle karşılaşmıştır. Terkos kıyı alanı doğal ve insan temelli nedenlerden dolayı erozyon ve göl ve denizin birleşme tehdidi altındadır. Terkos kıyı alanı 1883 yılında inşa edilen Terkos Gölü Baraj1 Havzası ile Karadeniz kıyısı arasında kalan Karaburun-Ormanl1 bölgesinde bulunmaktadır. Çalışma alanı Şekil 1'de verilmiştir.
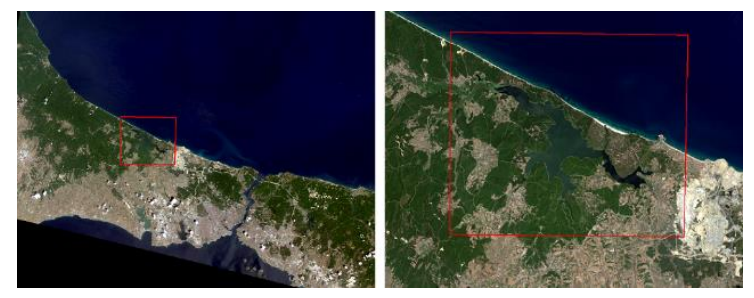

Şekil 1. Çalışma Alanı

\section{MATERYAL VE YÖNTEM}

Çalışmada 22 Temmuz 2016 tarihine ait Landsat-8 uydu görüntüsü kullanılmıştır. Landsat-8 görüntüsünün özellikleri Tablo 1' de verilmiştir (Landsat-8, 2017). Görüntüye öncelikle atmosferik düzeltme yapılmıştır.

Tablo 1. Landsat-8 Görüntüsünün Özellikleri (Landsat-8, 2017)

\begin{tabular}{|c|c|c|}
\hline Bantlar & Özellikleri & $\begin{array}{l}\text { Spektral Aralık } \\
(\mathrm{nm})\end{array}$ \\
\hline Bant 1 & $\begin{array}{l}30 \mathrm{~m} \\
\text { Coastal/Aerosol }\end{array}$ & $435-452$ \\
\hline Bant 2 & $30 \mathrm{~m}$ Blue & $452-512$ \\
\hline Bant 3 & $30 \mathrm{~m}$ Green & $533-590$ \\
\hline Bant 4 & $30 \mathrm{~m}$ Red & $636-673$ \\
\hline Bant 5 & $30 \mathrm{~m}$ NIR & $851-879$ \\
\hline \multirow[t]{2}{*}{ Bant 6} & 100m TIR-1 & $1060-1119$ \\
\hline & $100 \mathrm{~m}$ TIR-2 & $1150-1251$ \\
\hline Bant 7 & 30m SWIR-2 & $2107-2294$ \\
\hline Bant 8 & $15 \mathrm{~m}$ Pan & $503-676$ \\
\hline Bant 9 & 30m Cirrus & $1363-1384$ \\
\hline
\end{tabular}

Rastgele Orman siniflandırma algoritmas1, temelinde karar ağaçları olan bir makine öğrenmesi yöntemidir. (Breiman, 2001).

Karar ağaçları, eğitim verilerinin sınıflarını analiz eder ve test verilerinin hangi sinifa ait olduğunu eğitim verilerinden çıkarttığı kurallara göre belirler. Bu kurallar çok sayıda eğer-ise şartından oluşmaktadır.

Rastgele Orman algoritmasında kullanıcıdan iki parametre istenir. Bunlar, ağaç sayısı (N) ve ağaç yapısının oluşturulması için her düğümde kullanılacak değişken sayısı m'dir (Breiman, 2001). Parametreler seçildikten sonra test için ayrı bir veri seti yoksa eğitim veri setinin 2/3'ü öğrenme verisi (inBag), 1/3'ü test verisi (Out of-Bag (OOB)) olarak belirlenir. Her ağaç için boostrap tekniği kullanılarak önyüklemeli örneklem oluşturulur. Örneklemlerin inBag ve OOB verileri ayrılır. Sonra her bir örneklem için ağaç gelişimi başlar. Her düğümde tüm değişkenler arasından $\mathrm{m}$ sayıda rastgele seçilen değişkenler kullanılarak en iyi dallanma belirlenir. $\mathrm{Bu}$ işlem için CART (Classification and Regression Tree) algoritmas1 kullanılır (He, vd., 2015; Gislason, vd., 2006). CART algoritmas1 en iyi dalı belirlemek için formül (1) de verilen GINI indeksini kullanır (Gislason, vd., 2006).

$$
\sum \sum_{j \neq i}\left(f\left(C_{i}, T\right) /|T|\right)\left(f\left(C_{j}, T\right) /|T|\right)
$$

Denklemde $\mathrm{T}$ eğitim veri setini, $\mathrm{Ci}$ pikselin ait olduğu sınıfı, $f\left(C_{i}, T\right) /$ IT Iseçilen pikselin $C_{i}$ sınıfına ait olma olasılığını gösterir (Gislason, vd., 2006). GINI indeksi her dügümdeki örneklerin homojenliğini ölçer. Algoritma, her düğümde rastgele seçtiği değişkenler için GINI indeksini hesaplar. GINI İndeksinin küçük olduğu değişkeni seçerek diğer düğüme geçer. GINI indeksinin sifir olması durumunda ilgili dügüm tamamen homojendir ve dallanma orada biter (Gislason, vd., 2006). Böylelikle ağaçlar oluşturulmuş olur. Ağaçların ağırlıklarının belirlenmesi için Out of-Bag (OOB) test verileri kullanılır. OOB test verileri her bir ağaca yerleştirilir. Karar ağaçları her bir pikseli sınıflandırır. Sınıflandırma sonucuna göre her bir ağaç için OOB hatası hesaplanır. OOB hatası düşük 
olan ağaç yüksek ağırlık değeri alırken OOB hatası yüksek olan ağaç düşük ağırlık değeri alır (Akman, 2010).

Görüntüdeki tüm pikseller için her bir karar ağacı ağırlığına göre sinıflandırma oyu kullanır. Bir piksel için en çok oyu alan sınıf o piksele atanır. Sunulan çalışmada MATLAB yazılımının 2014b sürümü kullanılmıştır. Su alanları ve kara alanları olmak üzere iki sınıf belirlenmiş ve bu sınıflara ait eğitim pikselleri kaydedilmiştir. Rastgele Orman algoritmasında ağaçların oluşturulması için TreeBagger fonksiyonu kullanılmıştır. Algoritmanın parametreleri olan ağaç sayısı ve değişken sayısı 25 ve 2 olarak seçilmiştir ve tüm bant-setleri için aynı parametreler kullanılmıştır. Uygulanan bant setleri sırası ile R,G,B, NIR; NIR ve R,G,B dir.

Görüntüdeki her piksel oluşturulan karar ağaçlarına yerleştirilerek pikselin ait olduğu sınıf belirlenmiştir. $\mathrm{Bu}$ işlem için Matlab yazılımının Predict fonksiyonu kullanılmıştır. Örnek karar ağacı Şekil 2' de verilmiştir.

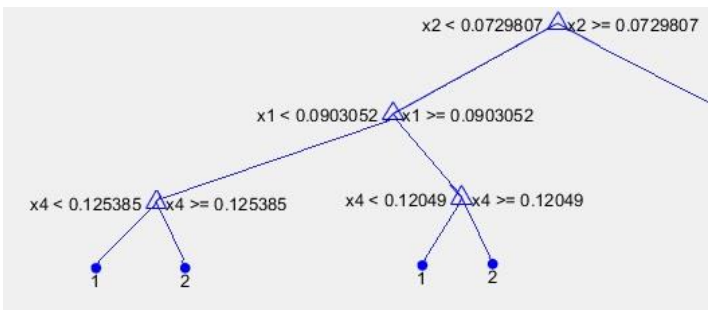

Şekil 2. Üretilen Karar Ağacı Örneği

Terkos Gölü için elde edilen sonuç ikili (binary) görüntüler Şekil 3,4 ve 5 'de gösterilmektedir.

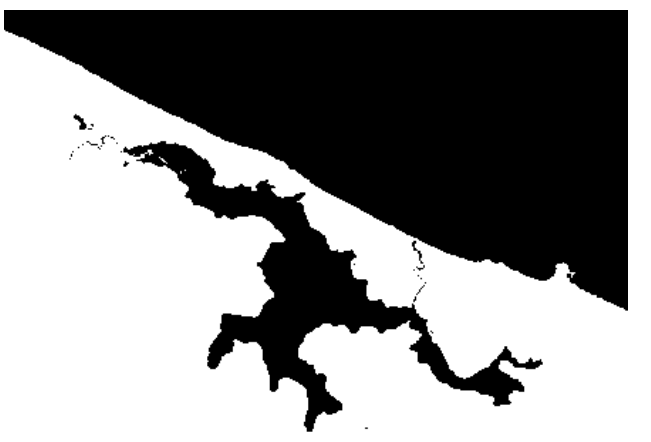

Şekil 3. R, G, B, NIR Bantları Kullanılarak Üretilen İkili Görüntü

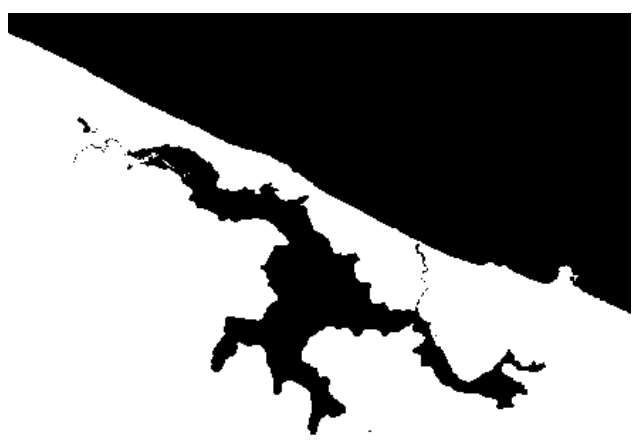

Sekil 4. NIR Bant Kullanılarak Üretilen İkili Görüntü

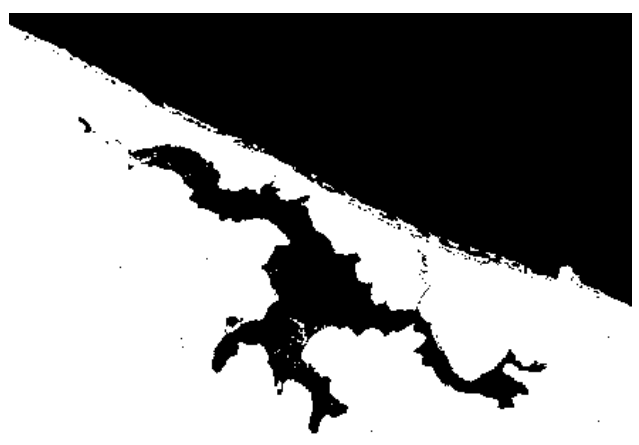

Sekil 5. R,G,B Bantları Kullanılarak Üretilen İkili Görüntü

\section{DOĞRULUK ANALIZİ}

Doğruluk analizi için elde edilen kıyı çizgisi ile elle sayısallaştırılan kıy çizgisi karşılaştırılmıştır. Bu amaç için Sayısal Kıyı Çizgisi Analiz Sistemi (DSAS-Digital Shoreline Analysis System) kullanılmıştır. (Thieler vd., 2009). DSAS referans bir veri ile istenilen kıyı çizgisini değerlendirmek amacıyla geliştirilmiş bir araçtır (JaysonQuashigah, vd, 2013). Çalışmada DSAS' in Net Kiyı Cizgisi Hareketi (Net Shoreline Movement (NSM)) modülü kullanılmıştır. Referans ve değerlendirilecek kıyı çizgisi arasında tanımlanan aralıklardaki kesitler boyunca dik uzaklıkların ölçülmesi ile kıyı çizgileri arasındaki farklar belirlenmiştir (Oyedotun, 2014).

Terkos Gölü'ne ait elde edilen kıyı çizgisi görüntülerinin doğruluklarını analiz etmek için alan karşılaştırması yapılmıştır. Bunun 
için öncelikle Terkos Gölü’nün sınırları elle sayısallaştırılmıştır. Sayısallaştırma sonucu vektör veri olarak kapalı bir poligon elde edilmiştir (Şekil 6).

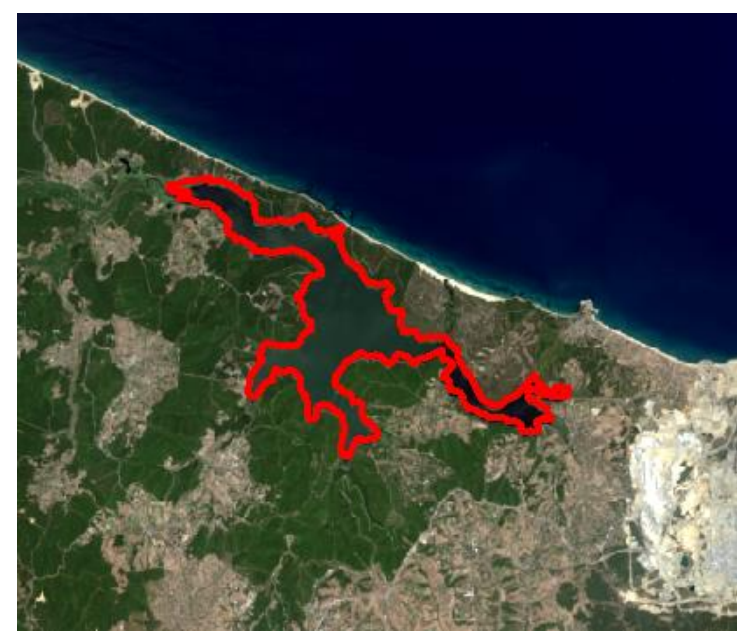

Şekil 6. Elle Sayısallaştırma Sonucu

Elde edilen poligonun alanı hesaplanarak referans alan bulunmuştur. Referans alan 31,068 km2 dir. Sonuç kıyı çizgisi görüntüleri de vektör formata çevrilerek alan hesaplanmıştır. Hesaplanan bu alanlar, elle sayısallaştırma sonucu üretilen alandan çıkartılarak alan farkları hesaplanmıştır. (Tablo 2.)

Tablo 2. Rastgele Orman Algoritmas1 Uygulanarak Elde Edilen Sonuçların Alanları Ve Referans Alandan Farkları

\begin{tabular}{lll}
\hline Veri Seti & $\begin{array}{l}\text { Alan } \\
\left(\mathrm{km}^{2}\right)\end{array}$ & $\begin{array}{l}\text { Alan } \\
\text { Fark1 } \\
\left(\mathrm{km}^{2}\right)\end{array}$ \\
\hline RGBNIR & 30.506 & 0.562 \\
RGB & 29.665 & 1.403 \\
NIR & 30.519 & 0.549 \\
\hline
\end{tabular}

DSAS'da doğruluk analizi uygulayabilmek için ana hat'a (baseline) ihtiyaç duyulmaktadır. Ana hat üretmek için elle sayısallaştırılan kıyı çizgilerine 100 metrelik tampon uygulanmıştır. Ana hat oluşturulduktan sonra $30 \mathrm{~m}$ 'de bir olacak şekilde kesitler kıyı çizgisine dik doğrultuda üretilmiştir. Kesit çizgilerinin boyları göl kıyı

çizgisi için 250 m, Karadeniz kıyı çizgisi için 500 m olarak seçilmiştir (Şekil 7 ve Şekil 8).

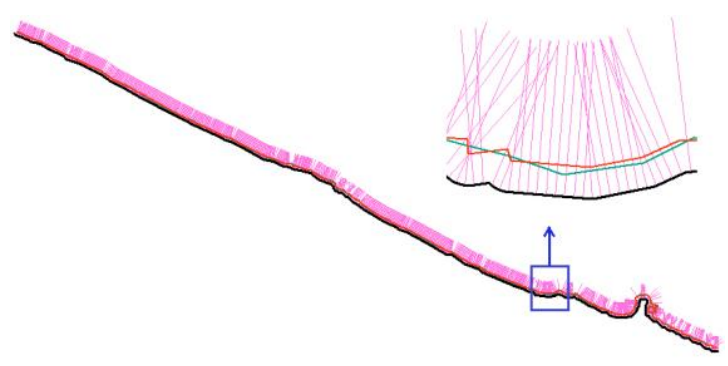

Şekil 7. Kırmızı: Elle Sayısallaştırma Sonucu, Yeşil: Kırmızı, Yeşil, Mavi Ve Kızıl Ötesi Bantlar İle Üretilen Kıyı Çizgisi, Pembe: Kesitler, Siyah: Ana Hat.

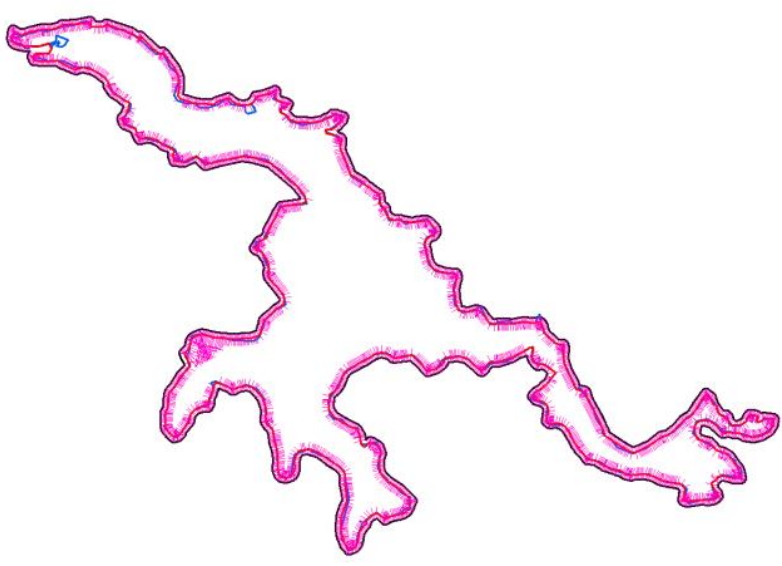

Şekil 8. Kırmızı: Elle Sayısallaştırma Sonucu, Mavi: Kırmızı, Yeşil, Mavi Ve Kızıl Ötesi Bantlar Ile Üretilen Kıyı Çizgisi, Pembe: Kesitler, Siyah: Ana Hat.

Sonuçlar ve referans kıyı çizgisi arasındaki dik mesafe farklarının ortalama hata ve karesel ortalama hata değerleri (2) ve (3) formülleri (Zhang, vd., 2013) kullanılarak hesaplanmıştır.

O. H. $=\frac{1}{n} \sum_{i=1}^{n}\left|X_{i}\right|$

(1)

K.O.H. $=\sqrt{\frac{1}{n} \sum_{i=1}^{n}\left(X_{i}-\underline{X}\right)^{2}}$ 
Göl kıyı çizgisi için hesaplanan ortalama ve karesel ortalama hatalar Tablo 3'de verilmiştir.

Tablo 3. Göl Kıyı Çizgisi İçin Rastgele Orman Algoritmas1 Sonucu Üretilen Kiyı Çizgilerinin Ortalama Ve Karesel Ortalama Hatalar1

\begin{tabular}{lll}
\hline Veri Seti & $\begin{array}{l}\text { Ortalama } \\
\text { Hata }(\mathrm{m})\end{array}$ & $\begin{array}{l}\text { Karesel } \\
\text { Ortalama } \\
\text { Hata }(\mathrm{m})\end{array}$ \\
\hline RGBNIR & 9.92 & 23.38 \\
RGB & 20.86 & 63.34 \\
NIR & 9.68 & 23.41 \\
\hline
\end{tabular}

Karadeniz kıyı çizgisi için hesaplanan ortalama ve karesel ortalama hatalar Tablo 4'de verilmiştir.

Tablo 4. Karadeniz Kıyı Çizgisi İçin Rastgele Orman Algoritması Sonucu Üretilen Kiyı Çizgilerinin Ortalama Ve Karesel Ortalama Hatalar1

\begin{tabular}{lll}
\hline Veri Seti & $\begin{array}{l}\text { Ortalama } \\
\text { Hata }(\mathrm{m})\end{array}$ & $\begin{array}{l}\text { Karesel } \\
\text { Ortalama } \\
\text { Hata }(\mathrm{m})\end{array}$ \\
\hline RGBNIR & 3.45 & 14.93 \\
RGB & 195.44 & 103.54 \\
NIR & 3.78 & 14.85 \\
\hline
\end{tabular}

\section{SONUÇLAR}

Önerilen Rastgele Orman algoritmas1 kullanılması sonucunda ve elle sayısallaştırma ile elde edilen sonuçlar üç farklı veri seti için karşılaștırıldığında: R,G,B,NIR bant seti ve yalnızca NIR bandının kullanılmasıyla elde edilen farklar sirasiyla 0.56 ve $0.55 \mathrm{~km} 2$ çıkmıștır. Terkos Gölü R,G,B,NIR ve NIR veri seti için hesaplanan karesel ortalama hatalar sirasiyla 23.38 ve $23.42 \mathrm{~m}$ olarak bir piksel boyutundan daha küçük olarak elde edilmiştir. Burada $68.62 \mathrm{~km}$ uzunluğunda olan göl çevresi için toplam 2236 kesit bazında elle sayısallaştırma verisi ile elde edilen sonuçlar karşılaştırılmıştır. Benzer şekilde $27.78 \mathrm{~km}$ uzunluğundaki Terkos kıyı şeridi için yapılan doğruluk analizi incelendiğinde toplam 884 kesitte R,G,B,NIR ve NIR veri seti karesel ortalama hatalar (14.93 m ve $14.85 \mathrm{~m}$ ) ve $1 / 2$ piksel büyüklügünde hesaplanmıştır. Buradan göl ve deniz kıyı çizgisinde oluşan farklılığın suyun içeriğinden kaynaklandığı sonucuna ulaşılmıştır.

Kıy1 çizgisi çıkartma ile ilgili tüm çalışmalarda NIR bandının avantajları bilinmektedir. Sunulan çalışmada bu bir kez daha ortaya konmuştur. Yine Rastgele Orman sinıflandırıcısı ile Landsat-8 görüntüsünden kıyı çizgisi elde edilebilmiștir. Çalıșmanın bir sonraki aşamasında 20 yıllık zaman farkına, beş yıl periyoda sahip Landsat görüntüleri kullanılarak elde edilen kıyı çizgileri bölgedeki dalga ve rüzgar verileri ile bütünleştirilecek, katı madde taşınım ve kıyı çizgisi modeli üretilecektir.

\section{TEŞEKKÜR}

Sunulan çalışma TUBİTAK tarafindan "Sürdürülebilir Kıyı Alanı İzleme Modeli İçin İnsansız Hava Araçları-Lidar Teknolojilerinin Entegrasyonu- Üç Boyutlu Otomatik Kıyı Çizgisi Çıkartılması Ve Analizi: İstanbul Terkos Örneği”" başlıklı TÜBİTAK Projesi (Proje No: 115Y718) kapsamında desteklenmiştir.

\section{KAYNAKÇA}

Akman, M. (2010). Veri Madenciliğine Genel Bakıș ve Random Forests Yönteminin İncelenmesi: Sağlık Alanında Bir Uygulama, Yüksek Lisans Tezi, Ankara Üniversitesi, Ankara.

Bayram B., Acar U., Seker D. Z., \& Ari A. (2008). A Novel Algorithm for Coast Line Fitting Through A Case Study Over Bosphorus. Journal of Coastal Research, 24(4), 983991.

Bayram B., Seker D. Z., Acar U., Yuksel Y., Guner, H. A. A., \& Cetin, I. (2013). An Integrated Approach to Temporal Monitoring of the Shoreline and Basin of Terkos Lake. Journal of Coastal Research, 29(6), 1427-1435.

Bayram B., Demir N., Ogurlu M., Catal R. H., \& Seker D. Z. (2016a). 3D Shoreline Extraction Using Orthophoto-Maps and LIDAR. In: 37 th Asian Conference on 
Remote Sensing (pp. 1-5). Sri Lanka, Colombo.

Bayram B., Avşar E. Ö., Şeker D. Z., Kayi A., Erdoğan M., Eker O., Janpaule I., \& Çatal R. H. (2017). The Role Of National And International Geospatial Data Sources In Coastal Zone Management. Fresenius Environmental Bulletin, 26(1), 383-391.

Bayram, B., Demir, N., Şeker, D. Z., Ogurlu, M., Oy, S., Bozkurt, S., \& İnce, A. (2016b). Mean-Shift Yöntemi ile LIDAR Intensity Verilerinden Kıyı Çizgisi Çıkartılması. Dünya CBS Günü (s.43). İstanbul, Türkiye.

Bendell, L. I., \& Wan, P. C. (2011). Application of aerial photography in combination with gis for coastal management at small spatial scales: a case study of shellfish aquaculture. Journal of Coastal Conservation, 15(4), 417-431.

Benumof, B. T., \& Griggs, G. B. (1999). The dependence of seacliff erosion rates on cliff material properties and physical processes: San Diego County, California. Shore Beach, 67(4), 29-41.

Breiman, L. (2001). Random forests. Machine learning, 45(1), 5-32.

Ding, X., \& Li, X. (2014). Coastline Detection in SAR Images Using Multiscale Normalized Cut Segmentation. In: 2014 IEEE International Geoscience and Remote Sensing Symposium (IGARSS), (pp. 44474449). Quebec City, Canada.

Dornbusch, U., Robinson, D. A., Moses, C. A., \& Williams, R. B. G. (2006). Chalk coast erosion and its contribution to the shingle budget in East Sussex. Zeitschrift für Geomorphologie, 144, 215-230.

Gens, R. (2010). Remote sensing of coastlines: detection, extraction and monitoring. International Journal of Remote Sensing, 31(7), 1819-1836.

Gislason, P. O., Benediktsson, J. A., \& Sveinsson, J. R. (2006). Random forests for land cover classification. Pattern Recognition Letters, 27(4), 294-300.

Guariglia, A., Buonamassa, A., Losurdo, A., Saladino, R., Trivigno, M. L., Zaccagnino, A., \& Colangelo, A. (2006). A multisource approach for coastline mapping \& identification of the shoreline changes. Annals of Geophysics, 49(1), 295-304.

He, J., Harris, J. R., Sawada, M., \& Behnia, P. (2015). A comparison of classification algorithms using Landsat-7 and Landsat- 8 data for mapping lithology in Canada's Arctic. International Journal of Remote Sensing, 36(8), 2252-2276.
Jayson-Quashigah, P. N., Addo, K. A., \& Kodzo, K. S. (2013). Medium resolution satellite imagery as a tool for monitoring shoreline change. Case study of the Eastern coast of Ghana. Journal of Coastal Research, 65(sp1), 511-516.

Kutser, T., Paavel, B. C., Verpoorter, C., Kauer, T., \& Vahtmäe, E. (2012). Remote sensing of water quality in optically complex lakes. In: Proceedings of the XXII Congress of the International Society for Photogrammetry and Remote Sensing (pp.165-169). Melbourne, Australia.

Landsat-8. Retrieved April 3, 2017, from https://landsat.gsfc.nasa.gov/landsat8/landsat-8- overview/

Li, R., K. Di., \& R. Ma. (2001). A Comparative Study of Shoreline Mapping Techniques. In: 4th International Symposium on Computer Mapping and GIS for Coastal Zone Management (pp. 53-60). Halifax, Nova Scotia, Canada.

Machado C. A. S., Beltrame A. M. K., Shinohara E. J., Giannotti M. A., Durieux L., Nobrega T. M. Q., \& Quintanilha J. A. (2014). Identifying concentrated areas of trip generators from high spatial resolution satellite images using object-based classification techniques. Applied Geography, 53, 271-283.

Marques, F. M. S. F. (2006). Rates, patterns, timing and magnitude-frequency of cliff retreat phenomena. A case study on the west coast of Portugal. Zeitschrift für GeomorphologieSupplementbände, 144, 231-257.

Oyedotun, T. D. T. (2014). Shoreline Geometry: DSAS as a Tool for Historical Trend Analysis. Geomorphological Techniques, Chap. 3, Sec. 2.2 (2014), 12.

Pardo-Pascual J. E., Almonacid-Caballer J., Ruiz L. A., \& Palomar-Vázquez, J. (2012). Automatic extraction of shorelines from Landsat TM and ETM+ multi-temporal images with subpixel precision. Remote Sensing of Environment, 123, 1- 11.

Pierre, G., \& Lahousse, P. (2006). The role of groundwater in cliff instability: an example at Cape Blanc-Nez (Pas-deCalais, France). Earth Surface Processes and Landforms, 31(1), 31-45.

Robert, K. V., Xiaoming, Q., Michael, R., McKayb, L., Minerb, J., Czajkowskic, K., Savinod, J., \& Bridgeman, T. (2004). Phycocyanin detection from LANDSAT TM data for mapping cyanobacterial blooms in Lake Erie. Remote Sensing of Environment, 89(3), 381-392. 
Schmitt, M., Lingyun, W., \& Xiao X. Z. (2015). Automatic Coastline Detection in Nonlocally Filtered TANDEM-X Data. In: Proceedings of IEEE International Geoscience and Remote Sensing Symposium (IGARSS) 2015, IEEE Xplore (pp. 1036-1039). Mailand, Italien.

Song C., Huang B., Ke L., \& Richards K. S. (2014). Remote sensing of alpine lake water environment changes on the Tibetan Plateau and surroundings: A review. ISPRS Journal of Photogrammetry and Remote Sensing, 92, 26-37.

Thieler, E. R., Himmelstoss, E. A., Zichichi, J. L., \& Ergul, A. (2009). The Digital Shoreline Analysis System (DSAS) version 4.0 - An ArcGIS extension for calculating shoreline change (No. 2008-1278). US Geological Survey.

Trochta J. T., Mouw C. B., \& Moore T. S. (2015). Remote sensing of physical cycles in Lake Superior using a spatio-temporal analysis of optical water typologies. Remote Sensing of Environment, 171, 149-161.

Yousef A., \& Iftekharuddin K. (2014). Shoreline extraction from the fusion of LiDAR DEM data and aerial images using mutual information and genetic algorithms. In: 2014 International Joint Conference on Neural Networks (IJCNN) (pp. 10071014). Beijing, China.

Yu S., Mou Y., Xu d., You X., Zhou L., \& Zeng W. (2013). A New Algorithm for Shoreline Extraction from Satellite Imagery with Non-Separable Wavelet and Level Set Method. International Journal of Machine Learning and Computing, 3(1), 158-163.

Zhang, T., Yang, X., Hu, S., \& Su, F. (2013). Extraction of coastline in aquaculture coast from multispectral remote sensing images: Object-based region growing integrating edge detection. Remote sensing, 5(9), 4470-4487.

Zheng G., Peng L., Tao G., \& Wang C. (2011). Remote sensing analysis of Bohai Bay West Coast shoreline changes. In: 2011 IEEE International Conference on Spatial Data Mining and Geographical Knowledge Services (ICSDM) (pp. 549552). Fuzhou, China. 